\title{
Comparación de tres pruebas serológicas para detectar infecciones por Paragonimus mexicanus en gatos infectados*
}

\section{Comparison of three serological tests to detect Paragonimus mexicanus infections in} infected cats

\author{
William R. Cornejo ${ }^{1,2}$, Pilar F. Alva ${ }^{1,2}$, Carlos R. Sevilla ${ }^{1}$, Alina F. Huiza ${ }^{1,2}$ \\ ${ }^{1}$ Departamento de Microbiología Médica, Facultad de Medicina, Universidad Nacional Mayor de San Marcos. \\ ${ }^{2}$ Instituto de Medicina Tropical "Daniel A. Carrión", Facultad de Medicina, Universidad Nacional Mayor de San Marcos. \\ * Trabajo realizado en el Servicio de Inmunología del Instituto de Medicina Tropical "Daniel A. Carrión", Facultad de Medicina, Universidad \\ Nacional Mayor de San Marcos.
}

\begin{abstract}
Resumen
Introducción: La paragonimiasis es una enfermedad pulmonar causada por tremátodes del género Paragonimus. Generalmente, el diagnóstico de laboratorio de la infección en humanos se realiza mediante la detección de huevos del parásito en esputo o heces; sin embargo, los resultados pueden ser negativos, necesitándose métodos diagnósticos alternativos. Objetivos: Comparar tres pruebas serológicas para la detección de anticuerpos contra el antígeno somático del estadio adulto de Paragonimus mexicanus (PmAS) en muestras de suero de gatos infectados experimentalmente. Diseño: Estudio experimental. Lugar: Bioterio del Instituto de Medicina Tropical "Daniel A. Carrión" de la Facultad de Medicina, Universidad Nacional Mayor de San Marcos. Material biológico: Gatos domésticos de 4 a 6 meses de edad y antígeno somático crudo de P. mexicanus (PmAS). Intervenciones: Se obtuvo muestras de sangre de 12 gatos domésticos infectados experimentalmente con $P$. mexicanus. Los sueros fueron evaluados por el inmunoensayo enzimático (ELISA), la doble difusión (DD) y contrainmunoelectroforesis (CIEF). Principales medidas de resultados: Se determinó el porcentaje de gatos que revelaron resultados positivos de acuerdo a los criterios establecidos. Resultados: Se encontró una buena correlación entre los resultados obtenidos por ELISA y aquellos obtenidos por CIEF o DD. La CIEF y el ELISA fueron más sensibles que la doble difusión. Con la CIEF y el ELISA, $81,8 \%$ (9/11) y 75,0\% (9/12) de los sueros evaluados dieron resultados positivos, respectivamente, mientras que $58,3 \%$ (7/12) de ellos fue positivo para la DD. Los sueros de 2 conejos con fasciolosis experimental dieron una reacción positiva con el antígeno PmAS por ELISA y CIEF. No se observó reacción cruzada cuando se usó sueros de gatos con dipilidiasis o de gatos sanos. Conclusiones: Estos resultados indican que la CIEF y el ELISA, que emplean antígeno somático crudo, son pruebas de similar sensibilidad para el diagnóstico de paragonimiosis, pero no pueden ser usadas para el diagnóstico diferencial de las infecciones por $P$. mexicanus y $F$. hepatica, debido a la ocurrencia de reacciones cruzadas.
\end{abstract}

Palabras clave: Paragonimiosis, doble difusión, contrainmunoelectroforesis, ELISA, Paragonimus mexicanus.

Abstract

Background: Paragonimiasis is a lung disease caused by Paragonimus trematodes genus. Human infection laboratory diagnosis is usually done by detection of parasite eggs in sputum or feces; however, findings may be negative and alternative diagnostic methods are required. Objectives: To compare three serologic tests for detection of Paragonimus mexicanus somatic antigen (PmAS) antibodies in serum samples of cats infected experimentally. Design: Experimental study. Setting: Instituto de Medicina Tropical "Daniel A. Carrión" bioterium, Faculty of Medicine, Universidad Nacional Mayor de San Marcos, Lima, Peru. Biologic material: Domestic cats 4-6 years old and P. mexicanus (PmAS) crude somatic antigen. Interventions: Blood samples were collected from twelve domestic cats infected with $P$. mexicanus. Serum samples were evaluated by enzyme-linked immunosorbent assay (ELISA), double diffusion (DD) and counterimmunoelectrophoresis (CIE). Results: Good correlation was found between ELISA results and those of CIE or DD. Both CIE and ELISA were more sensitive than DD. With CIE and ELISA sera were respectively positive $81.8 \%(9 / 11)$ and $75.0 \%(9 / 12)$, whereas $58.3 \%$ (7/12) were positive for DD test. Sera from 2 rabbits with experimental fascioliosis had positive reaction with PmAS antigen by both ELISA and CIE tests. No cross-reactivity was observed using sera from cats with dipylidiasis or from healthy cats. Conclusions: Results showed that both ELISA and CIE were equally sensitive tests for paragonimiosis diagnosis but could not be used for differential diagnosis of $P$. mexicanus and $F$. hepatica infections due to cross-reaction.

Key words: Paragonimiosis, doble diffusion test, counterimmunoelectrophoresis, ELISA, Paragonimus mexicanus.

An Fac med. 2012;73(1):29-33

\section{INTRODUCCIÓN}

Paragonimus mexicanus fue originalmente comunicado en el Perú por Miyasaki, Ibáñez y Miranda ${ }^{(1)}$, en 1969, al estudiar adultos de Paragonimus extraídos de pulmones de gatos procedentes de La Asunción y el Guayo en Cajamarca.
Ha sido casi totalmente determinado el ciclo de vida completo del parásito. El primer huésped intermediario correspondería al caracol Aroapyrgus colombiensis ${ }^{(2)}$, el cual no ha sido encontrado infectado naturalmente a pesar de haberse estudiado miles de ejemplares; sin embargo, se ha podido infectarlo en el laboratorio ${ }^{(3)}$. El segundo hospedero intermediario es el cangrejo de río Hypolobocera chilensis eigenmanni, de amplia distribución en Cajamarca y usado en la alimentación humana ${ }^{(2)}$. La infección del huésped definitivo se realiza por la ingesta de cangrejos, crudos o insuficientemente cocidos, infectados 
con metacercarias del parásito. El hospedero definitivo habitual es principalmente el gato doméstico y el hospedero definitivo accidental es el hombre. El uso del gato doméstico como animal de experimentación ha permitido conocer algunos aspectos de la biología del parásito ${ }^{(4-6)}$ y la histopatología de la enfermedad ${ }^{(7)}$; sin embargo, poco es lo que se conoce acerca de la antigenicidad y de la respuesta inmunitaria provocada por P. mexicanus ${ }^{(8,9)}$.

La paragonimiosis humana causada por P. mexicanus es aún una importante enfermedad endémica en algunas partes de las Américas, particularmente en Ecuador y Perú ${ }^{(10,11)}$. El diagnóstico de la paragonimiosis se basa en el hallazgo de huevos de Paragonimus en el esputo y/o heces. Las pruebas inmunoserológicas son útiles en el diagnóstico de la infección por Paragonimus, especialmente cuando el esputo y las heces son negativas, y en la evaluación del tratamiento quimioterapéutico de la parasitosis ${ }^{(12-14)}$. Las personas y los animales como gatos domésticos y ratas infectados con Paragonimus producen anticuerpos precipitantes que pueden ser detectados por varias pruebas, que incluyen la inmunodifusión doble (DD), la inmunoelectroforesis y la contrainmunoelectroforesis (CIEF) ${ }^{(9,15,16)}$. Recientemente, el inmunoensayo enzimático (ELISA) también ha sido adaptado para el serodiagnóstico de la paragonimiosis en personas y en animales de experimentación ${ }^{(13,14,16)}$.

El presente estudio fue llevado a cabo para comparar dos pruebas de precipitación, DD y CIEF, y la prueba de ELISA para el diagnóstico de la paragonimiosis en gatos infectados experimentalmente, empleando un extracto total del estadio adulto de $P$. mexicanus como antígeno.

\section{MÉTODOS}

Para la infección experimental se obtuvo metacercarias del hepatopáncreas de cangrejos de la especie $H$. chilensis e identificadas como P. mexicanus, de acuerdo a las características previamente comunicadas ${ }^{(17)}$. Los cangrejos fueron colectados en el valle de Condebamba, un área endémica de paragonimiosis en el Perú. Las metacercarias obtenidas fueron lavadas 2 a 3 veces con solución salina fisiológica estéril e inoculadas por vía oral a 12 gatos domésticos de 2 a 3 meses de edad, libres de infección intestinal y de ectoparásitos, con una pipeta Pasteur curva de punta roma ${ }^{(4)}$. El número de metacercarias inoculadas fue de 20 a 30 por cada gato. Al cabo de 2 a 4 meses, los animales fueron sacrificados para la obtención de los parásitos adultos. El examen de heces se realizó por el método directo y por sedimentación rápida, a partir del día 35 posterior a la infección. Los parásitos fueron recuperados de los pulmones de los gatos infectados ${ }^{(5)}$.

El antígeno fue preparado por homogenización y extracción de los parásitos adultos en buffer citrato 0,2 M, pH 4,9, utilizando un homogenizador teflónvidrio, en baño de hielo. La suspensión obtenida fue centrifugada a $15000 \mathrm{rpm}$ por 30 minutos, a $4 \stackrel{\circ}{-}$; el sobrenadante fue colectado, distribuido en alícuotas y guardado a $-20 \stackrel{\circ}{ } \mathrm{C}$ hasta su uso. El dosaje de proteínas de la fracción sobrenadante del antígeno somático de P. mexicanus, denominada PmAS, se realizó de acuerdo al método de FolinCiocalteus ${ }^{(18)}$.

El antígeno somático extraído de $P$. mexicanus fue analizado utilizando el sistema discontinuo SDS-PAGE (19), con un gel al 15\%. El antígeno PmAS fue mezclado con un volumen igual de tampón Tris- $\mathrm{HCl} 0.5 \mathrm{M}, \mathrm{pH}$ 6,8, conteniendo 2-mercaptoetanol 0,1 M, SDS al $2 \%$, glicerol al $40 \%$ y azul de bromofenol al 0,01\%, y la mezcla fue hervida por 3 minutos. Un volumen de $10 \mu \mathrm{L}$ del antígeno, conteniendo aproximadamente $6 \mu \mathrm{g}$ de proteína, fue aplicado a cada carril del gel. Como marcadores de peso molecular se usó una mezcla de seis proteínas conteniendo fosforilasa b (94 000), albúmina (67 000), ovoalbúmina (43 000), anhidrasa carbónica (30 000), inhibidor de la tripsina (20 100) y alfa lactoalbúmina (14 400).
Luego de la electroforesis, el gel fue teñido por el método de tinción de plata ${ }^{(20)}$.

La obtención de sueros de gato se realizó mediante la sangría total de 12 animales infectados experimentalmente con P. mexicanus, bajo anestesia con éter, antes de ser sacrificados para la colección de los parásitos adultos. Los sueros fueron obtenidos por centrifugación a $2500 \mathrm{rpm}$ por 5 a $10 \mathrm{minu}$ tos, luego distribuidos en alícuotas y guardados a $-20^{\circ} \mathrm{C}$. Los sueros de dos gatos naturalmente infectados con $\mathrm{Di}$ pylidium caninum y de seis gatos libres de infección fueron obtenidos a partir de la sangría parcial de la vena safena, y posterior centrifugación a $2500 \mathrm{rpm}$ durante 5 a 10 minutos. Los sueros fueron distribuidos en pequeños volúmenes y guardados a $-20^{\circ} \mathrm{C}$ hasta su uso.

Se obtuvo los sueros de conejo conteniendo anticuerpos anti-Fasciola hepatica de dos conejos Nueva Zelanda infectados oralmente con 25 metacercarias de F. hepatica, y sangrados luego que los animales alcanzaran la fase crónica de la infección. Los sueros fueron guardados en alícuotas a $-20 \stackrel{\circ}{\mathrm{C}}$ hasta su uso.

Se llevó a cabo tres pruebas serológicas. La prueba de DD de Ouchterlony se realizó sobre láminas de vidrio cubiertas con agarosa al 1\% disuelta en tampón salino fosfato (PBS) 0,01 M, $\mathrm{pH} 7,2$, conteniendo azida de sodio al $0,02 \%{ }^{(21)}$. El antígeno PmAS fue empleado a la concentración de 2,9 mg/ mL. La prueba de CIEF fue llevada a cabo de acuerdo al método de $\mathrm{Hi}$ llyer ${ }^{(22)}$, con algunas modificaciones. Las láminas fueron cubiertas con agarosa de alta electroendósmosis al 1\%, disuelta en tampón barbital 0,06 M, $\mathrm{pH} 8,6$, conteniendo azida de sodio al $0,02 \%$. El diámetro de los pocillos y la distancia entre ellos fue de $3 \mathrm{~mm}$. Las láminas fueron sometidas a $100 \mathrm{~V}$ de corriente eléctrica por 30 minutos, leídas inmediatamente después de la corrida y luego de 24 horas de incubación en cámara húmeda. La concentración del antígeno PmAS empleada en 
Tabla 1. Detección de anticuerpos en los sueros de gatos infectados experimentalmente con $P$. mexicanus mediante las técnicas de doble difusión, contrainmunoelectroforesis y ELISA.

\begin{tabular}{|c|c|c|c|c|}
$\begin{array}{c}\text { Suero de gato } \\
\text { Nro. }\end{array}$ & \multicolumn{2}{c}{ CIEF } & + & + \\
\hline 1 & + & + & + & + \\
\hline 2 & + & + & - & - \\
\hline 3 & - & NE & + & + \\
\hline 4 & + & + & - & - \\
\hline 5 & - & - & + & + \\
\hline 6 & - & + & - & + \\
\hline 7 & - & - & + & + \\
\hline 8 & + & + & + & + \\
\hline 9 & - & + & + & + \\
\hline 10 & + & + & + & + \\
\hline 11 & + & + & + & 75,0 \\
\hline 12 & + & + & 75,0 & + \\
\hline$\%$ Positividad & 58,3 & 81,8 & & + \\
\hline
\end{tabular}

$(+)$ : positivo ; (-) : negativo; NE : no evaluado.

la prueba fue $2 \mathrm{mg} / \mathrm{mL}$. La prueba de ELISA se realizó de acuerdo al procedimiento de Langley y Hillyer ${ }^{(23)}$, con algunas modificaciones. Los pocillos de las placas de polipropileno fueron cubiertas con el antígeno diluido en tampón carbonato-bicarbonato $0,05 \mathrm{M}, \mathrm{pH}$ 9,6 , e incubadas a $4 \stackrel{\circ}{\circ} \mathrm{C}$ por toda la noche. El exceso de antígeno fue retirado de las placas mediante tres lavados con PBS conteniendo Tween 20 al 0,05\% (PBS-T), a intervalos de 3 minutos. A continuación, los pocillos fueron bloqueados con PBS conteniendo Tween 20 al 0,3\% y las placas fueron incubadas en cámara húmeda a $37^{\circ} \mathrm{C}$ por 1 hora. Luego del lavado de las placas, se agregó los sueros de gato a evaluar, incubándose las placas a $37^{\circ} \mathrm{C}$ por 1 hora. Los anticuerpos que no reaccionaron fueron lavados con PBS-T. Para la detección de los sueros se usó dos conjugados: anti-IgG de gato-biotina (conjugado 1) y peroxidasa-extravidina (conjugado 2), los cuales fueron agregados uno tras otro luego de incubarse por separado a $37^{\circ} \mathrm{C}$ por 1 hora. El exceso de cada conjugado se eliminó a través de los lavados con PBS-T. La prueba fue revelada con el sustrato/cromógeno peróxido de hidrógeno/ortofe- nilendiamino, a temperatura ambiente. La reacción fue detenida a los $30 \mathrm{mi}$ nutos por adición de ácido sulfúrico al 12,5\%. Las placas fueron leídas en un lector de micro-ELISA a $492 \mathrm{~nm}$ (Titertek Multiskan plus versión 2,01). La concentración del antígeno PmAS fue de $10 \mu \mathrm{g} / \mathrm{mL}$, la dilución de los sueros de gato $1: 25$ y los conjugados 1 y 2 fueron usados a las diluciones de 1:4000 y 1:1000, respectivamente. El volumen de todos los reactivos fue de $100 \mu \mathrm{L} / \mathrm{po}$ cillo, excepto para la solución de ácido sulfúrico, que fue de $50 \mu \mathrm{L} /$ pocillo. La concentración del antígeno, la dilución de los sueros y las diluciones de los conjugados fueron determinadas mediante la titulación en tablero de damas. Para la evaluación de los sueros de conejo se siguió el mismo procedimiento, excepto que la dilución de los sueros fue 1:200 y se usó el conjugado anti-IgG de conejoperoxidasa diluido 1:1000.

Las pruebas de precipitación fueron consideradas positivas cuando se detectó al menos una línea de precipitación. La prueba de ELISA fue considerada positiva cuando el valor de absorbancia de los sueros problema estuvo por encima del valor de absorbancia promedio de los sueros normales (X) más dos desviaciones estándar (DE). Cada suero fue evaluado por duplicado y expresado como un valor promedio de absorbancia.

\section{RESULTADOS}

En los 12 gatos infectados, el porcentaje de recuperación de los parásitos adultos luego de la inoculación con metacercarias varió entre $40 \%$ y $85 \%$, con un promedio de $73,1 \%$. Todos los parásitos recuperados fueron adultos maduros y fueron obtenidos solo de los pulmones.

En la SDS-PAGE los antígenos de los parásitos extraídos con tampón citrato revelaron al menos 11 bandas proteicas, con pesos moleculares relativos que variaron de $<14400$ a 30000 daltons.

Los sueros de 12 gatos infectados experimentalmente fueron evaluados por pruebas de precipitación, obteniéndose un porcentaje de positividad de 58,3\% (7/12) por DD y $81,8 \%$ (9/11) por CIEF. Considerando los resultados de las dos pruebas, se obtuvo un porcentaje de positividad de 75,0\% (9/12) (tabla 1). Mediante la técnica de DD se detectó 1 a 2 bandas de precipitación en los sueros de los gatos que dieron una reacción positiva, predominando los sueros que revelaron una banda de precipitación. Por la técnica de CIEF, los sueros de gato mostraron 1 a 2 bandas de precipitación, excepto en un caso en que se observó tres líneas de precipitación. La especificidad de las pruebas de DD y CIEF fue evaluada al emplearse dos sueros de gatos naturalmente infectados con D. caninum y dos sueros de conejo infectados experimentalmente con F. hepatica. Los sueros de seis gatos libres de infección, usados como control negativo, y los sueros de dos gatos infectados con D. caninum no revelaron reacción cruzada (ausencia de líneas de precipitación) en ambas pruebas. Sin embargo, los sueros de dos conejos con fasciolosis dieron una reacción positiva en la CIEF, evidenciada por la aparición de una línea de precipitación, aunque la DD fue negativa en ambos casos. 
Tabla 2. Valores de absorbancia obtenidos en la prueba de ELISA para $P$. mexicanus contra los sueros de gatos con paragonimiosis, animales con otras infecciones por helmintos y gatos sanos.

\begin{tabular}{cccc} 
Grupo de sueros & $\mathrm{N}^{0}$ de muestras & $\mathrm{A}_{492 \mathrm{~nm}}$ & $\mathrm{~N}^{0}$ de positivos* \\
$\begin{array}{c}\text { P. mexicanus } \\
\text { (rango) }\end{array}$ & 12 & $0,44 \pm 0,51$ & 9 \\
F. hepatica & 2 & $(0,130-1,72)$ & 2 \\
D. caninum & 2 & 0,216 & 0 \\
$\begin{array}{c}\text { Controles sanos } \\
\text { (rango) }\end{array}$ & 6 & 0,03 & 0 \\
\hline
\end{tabular}

* Un resultado fue considerado positivo cuando el valor de absorbancia a $492 \mathrm{~nm}$ fue mayor que el correspondiente a $\mathrm{X} \pm 2 \mathrm{DE}$ de los controles sanos.

La técnica de ELISA detectó anticuerpos anti-Paragonimus en 9 de 12 sueros de gato analizados (75\%) (tabla 1). Los valores de absorbancia de los sueros de gatos infectados con $P$. mexicanus, de animales con otras infecciones y de los animales sanos, son presentados en la tabla 2. Los valores de absorbancia de los sueros positivos variaron entre 0,13 y 1,72 . El valor de corte de la prueba fue 0,091 ( $\mathrm{X}+2$ $\mathrm{DE}$, controles negativos). Los sueros de los animales con dipilidiasis resultaron negativos, pero los sueros de los animales con fasciolosis revelaron resultados falso positivos (tabla 2).

\section{DISCUSIÓN}

Los métodos inmunoserológicos -como la intradermorreacción, fijación de complemento, inmunoelectroforesis y doble difusión- han sido muy utilizados para el diagnóstico de la paragonimiosis ${ }^{(12,15,16)}$. La CIEF es una prueba de interés para el inmunodiagnóstico de infecciones parasitarias, debido a que es una prueba rápida, sencilla, sensible y que requiere de pequeños volúmenes de los reactantes. La CIEF ha sido especialmente usada como prueba diagnóstica de trematodiasis, como en los casos de fasciolosis humana y animal ${ }^{(22,24,25)}$, pero escasamente evaluada en paragonimiosis humana y animal ${ }^{(9,26)}$. La prueba de ELISA ha sido también utilizada en paragonimiosis y es considerada como un método más confiable y útil $(13,14,27)$. La prueba ha demostrado ser útil no solo para el diagnóstico sino también para la evaluación de la cura terapéutica de la enfermedad ${ }^{(13,14)}$.

La mayoría de las pruebas inmunoserológicas empleadas para el diagnóstico de paragonimiasis usan extractos totales de parásitos adultos como fuente de antígeno. Los parásitos han sido extraídos con agua destilada, solución salina fisiológica, tampón veronal salino, tampón fosfato salino, tampón citrato o solución salina al 0,1\% ${ }^{(16,27-30)}$. En algunos estudios, los parásitos fueron delipidados previo a la extracción del antígeno ${ }^{(16,27)}$. En este estudio, el extracto soluble crudo con tampón citrato de los parásitos adultos fue usado sin delipidación. Su análisis por electroforesis demostró la presencia de 11 polipéptidos de peso molecular bajo, resultados diferentes de los encontrados por Barquín y cols. ${ }^{(8)}$, quienes trabajando con un extracto de P. mexicanus hallaron 13 bandas proteicas comprendidas entre 10000 y 101000 daltons. Comparado a los $33 \mu \mathrm{g}$ de antígeno usado por Barquín y cols., la menor concentración de antígeno usado en nuestro estudio $(6 \mu \mathrm{g})$ puede haber sido la causa de las diferencias encontradas. De manera similar, Sugiyama y cols. ${ }^{(28)}$ caracterizaron el antígeno somático de $P$. westermani por electroforesis, encontrando 36 bandas proteicas con pesos moleculares entre 10100 y 103000 daltons. La diferencia entre este estudio y el nuestro puede deberse al empleo de solucio- nes tampón de extracción antigénica diferentes; ellos usaron tampón salino veronal y nosotros tampón citrato. Así mismo, esta diferencia puede deberse a que se trabajó con especies diferentes.

La DD reveló 0 a 2 bandas de precipitación, resultados similares a los envontrados por Barquín y cols. ${ }^{(8)}$, pero diferentes a los de Yogore y cols. ${ }^{(15)} \mathrm{y}$ Seed y cols. ${ }^{(31)}$, quienes detectaron de 2 a 5 y de 0 a 5 bandas de precipitación en gatos infectados experimentalmente con $P$. westermani y P. kellicotti, respectivamente. Estas diferencias en el número de bandas pueden ser debidas a que se trabajó con diferentes especies de Paragonimus, a los tiempos variables de infección de los gatos y a las diferentes condiciones empleadas en la prueba.

Aunque menos sensible que el ELISA, la DD mostró una buena correlación con esta prueba; los siete sueros positivos por DD también lo fueron por la prueba de ELISA. Similares resultados han sido encontrados en el serodiagnóstico de la paragonimiosis westermani en humanos (13,14). Más aún, el porcentaje de positividad de la DD fue mayor cuando los valores de absorbancia del ELISA fueron altos $(>0,30)^{(14)}$.

La comparación entre la sensibilidad del ELISA y la CIEF mostró que ambas pruebas fueron igualmente sensibles en la detección de la respuesta de anticuerpos en los animales infectados, y significativamente más sensibles que la prueba de DD. Similar sensibilidad para el ELISA y la CIEF ha sido comunicada para la detección de anticuerpos en ratones y conejos infectados con F. hepatica ${ }^{(22)}$, aunque los anticuerpos fueron detectados más tempranamente por la prueba de ELISA. No se ha informado una comparación directa previa entre ambas técnicas, para el caso de paragonimiosis animal, habiéndose evaluado por separado la CIEF y la prueba de ELISA para la detección de anticuerpos , tanto en gatos experimentalmente infectados ${ }^{(9,16,28)}$ como en humanos naturalmente infectados ${ }^{(13,14,26)}$ con Paragonimus sp. 
La evaluación de la especificidad de las pruebas reveló reacción cruzada con los sueros de animales con fasciolosis, al ser evaluados por CIEF y ELISA. Estos resultados confirman otros estudios de que hay reacción cruzada entre los antígenos somáticos no purificados de Paragonimus y los sueros de animales o humanos con fasciolosis $(27,32,33)$.

Nuestros resultados indican que la prueba de ELISA y la CIEF, empleando antígeno somático crudo de P. mexicanus, son pruebas de similar sensibilidad para el diagnóstico de paragonimiosis, pero no pueden ser usados para el diagnóstico específico de paragonimiosis. Para mejorar la especificidad de estas pruebas es necesario obtener antígenos purificados específicos que puedan ser evaluados en el modelo animal o con sueros humanos provenientes de casos parasitológicamente confirmados.

\section{REFERENCIAS BIBLIOGRÁFICAS}

1. Miyazaki I, Ibáñez N, Miranda H. On a new lung fluke found in Peru, Paragonimus peruvianus (Trematoda: Troglotrematidae). Jap J Parasitol. 1969;18:123-30.

2. Huiza A, Tantalean M. Paragonimus y paragonimiasis en el Perú. Bol Med Trop (Lima). 1986;5:33-9.

3. Malek EA, Ibáñez N, Guerra A. Description of redia and cercaria of Paragonimus peruvianus from experimentally infected Aroapyrgus colombiensis of Condebamba Valley, Peru. J Parasitol. 1985;71:253-6.

4. Tantalean M, Náquira C, Huiza A, Delgado AE. La vía de penetración de la larva de Paragonimus peruvianus en animales de experimentación. Rev Inst Med Trop S Paulo. 1974;16:332-6.

5. Ibañez N, Miranda H, Fernández E, Cuba C. Paragonimus y Paragonimiasis en el Norte Peruano. Proceso del desarrollo de Paragonimus peruvianus Miyasaki, Ibáñez y Miranda, 1969 en Felis cati L. gato doméstico infectado experimentalmente. Rev Per Biol. 1974;1:31-56.

6. Tantalean M, Huiza A. La ruta migratoria de la larva de Paragonimus mexicanus Miyasaki e Ishii, 1968 , en el gato doméstico infectado experimentalmente. Rev Ciencias UNMSM. 1986;74:63-9.

7. Retamozo L, Tantalean M, Huiza A. Lesiones histológicas en pulmón de gato doméstico inoculado experimentalmente con Paragonimus peruvianus. Rev Per Med Trop UNMSM. 1974-1975;3-4:32-41.

8. Barquin N, Lamothe R, Flisser A. Paragonimus mexicanus: an antigenic analysis. Bol Chil Parasitol. 1982;37:42-6.

9. Cornejo W, Ticlla ED, Tantalean M, Huiza A. Detección de anticuerpos en gatos infectados con Paragonimus mexicanus mediante la contrainmunoelectroforesis. Rev Per Med Trop UNMSM. 1994;8:53-5.

10. Hillyer GV, Apt W. Food-borne trematode infections in the Americas. Parasitol Today. 1997;13:87-8.

11. Procop GW. North American Paragonimiasis (caused by Paragonimus kellicotti) in the context of global paragonimiasis. Clin Microbiol Rev. 2009;22:415-46.

12. Yokogawa M. Paragonimus and paragonimiasis. Adv Parasitol. 1965;3:99-158.

13. Yokogawa M, Kojima S, Kobayashi M, Hata H, Ito J Tsuji M, et al. Peruvian paragonimiasis: diagnostic value of the enzyme-linked immunosorbent assay (ELISA). Jap J Parasitol. 1983;32:317-22.

14. Imai J. Evaluation of ELISA for the diagnosis of paragonimiasis westermani. Trans R Soc Trop Med Hyg. 1987;81:3-6.

15. Yogore MG, Lewert RM, Madraso ED. Immunodiffusion studies on paragonimiasis. Am J Trop Med Hyg. 1965;14:586-91.

16. Quicho L, Thammapalerd N, Tharavanij S, Vajrasthira S. Humoral immune response of cats to Paragonimus infection. Southeast Asian J Trop Med Pub Health. 1981;12:364-70.

17. Miyasaki I, Ibañez N, Miranda H. Studies on the metacercariae of Paragonimus peruvianus (Trematoda: Troglotrematidae). Jap J Parasitol. 1971;20:425-30.

18. Lowry O, Rosenbrough NJ, Farr AL, Randall RJ. Protein measurement with the Folin phenol reagent. J Biol Chem. 1951;193:265-75.

19. Laemmli UK. Cleavage of structural protein during the assembly of the head of bacteriophage T4. Nature (London). 1970;227:680-5.

20. Wray W, Boulikas T, Wray VP y Kancocl JR. Silver staining of proteins in polyacrylamide gels. Anal Biochem. 1981;118:197-203.

21. Crowle AJ. Precipitin and microprecipitin reactions in fluid medium and in gels, p. 3-14. En: Rose N R, Friedman $\mathrm{H}$ (ed.), Manual of clinical immunology, 2da. Ed. Washington: American Society for Microbiology. 1980.

22. Hillyer GV. Use of counterelectrophoresis to detect infections of Fasciola hepatica. J Parasitol. 1975;61:557-9.
23. Langley R, Hillyer GV. Detection of circulating parasite antigen in murine fascioliasis by two-site enzyme-linked immunosorbent assay. Am J Trop Med Hyg. 1989;41:472-8.

24. Levine DM, Hillyer GV, Flores SI. Comparison of counterelectrophoresis, the enzyme-linked immunosorbent assay, and the Kato fecal examination for the diagnosis of fascioliasis in infected mice and rabbits. Am J Trop Med Hyg. 1980;29:602-8.

25. Mikhail EM, Farid Z, Youssef FG, Mansour NS. Counterimmunoelectrophoresis for the rapid and specific diagnosis of acute fascioliasis and schistosomiasis. Trans R Soc Trop Med Hyg. 1990;84:400-1.

26. Cornejo W, Náquira, Espinoza Y, Huiza A, Sevilla C. La paragonimosis en escolares del valle de Condebamba, Cajamarca-Perú. An Fac Med (UNMSM). 1994;8:53-5.

27. Pariyanonda S, Maleewong W, Pipitgool V, Wongkham C, Morakote N, Intapan P, et al. Serodiagnosis of human paragonimiasis caused by Paragonimus heterotremus. Southeast Asian J Trop Med Public Health. 1990;21:103-7.

28. Sugiyama H, Sugimoto M, Akasaka K, Horiuchi T, Tomimura T, Kozaki S. Characterization and localization of Paragonimus westermani antigen stimulating antibody formation in both the infected cat and rat. J Parasitol. 1987;73:363-7.

29. Indrawati I, Chaicumpa W, Setasuban P, Ruangkunaporn Y. Studies on immunodiagnosis of human paragonimiasis and specific antigen of Paragonimus heterotremus. Int J Parasitol. 1991;21:395-401.

30. Wongkham C, Maleewong W, Intapan P, Morakote N, Chaicumpa W. Partially purified antigens of Paragonimus heterotremus for serodiagnosis of human paragonimiasis. Southeast Asian J Trop Med Public Health. 1994;25:176-80.

31. Seed JR, Sogandares-Bernal F, Mills R. Studies on American paragonimiasis. II. Serological observations of infected cats. J Parasitol. 1966;32:358-62.

32. Waikagul J. Serodiagnosis of paragonimiasis by enzyme-linked immunosorbent assay and immunoelectrophoresis. Southeast Asian J Trop Med Public Health. 1989;20:243-51.

33. Hillyer GV, Serrano AE. The antigens of Paragonimus westermani, Schistosoma mansoni, and Fasciola hepatica adult worms. Am J Trop Med Hyg. 1983;32:350-8.

\section{Correspondencia:}

William R. Cornejo Medina

Departamento de Microbiología Médica, UNMSM

Calle José Santos Chocano 199. Urb. San Joaquín Callao 02, Perú

E-mail: wcormed@hotmail.com 